Editorial

\title{
Revista Acta Colombiana de Psicología
}

\author{
Ernesto L. Ravelo-Contreras ${ }^{*}$
}

Respetados lectores de Acta Colombiana de Psicología.

Desde nuestra revista -que fue una de sus grandes iniciativas- rendimos un sentido homenaje póstumo a nuestro director, el Dr. Carlos Vargas Ordóñez, quien falleció el pasado 24 de mayo. Como decano de la Facultad de Psicología de la Universidad Católica de Colombia, el Dr. Vargas fundó la revista Acta colombiana de Psicología y durante 20 años lideró esta publicación que es hoy reconocida como una de las de mayor impacto en el campo de la Psicología, brindando siempre su acertada orientación, así como su decidido y permanente apoyo.

Hace más de 20 años, el Dr. Vargas tuvo un sueño para nuestra querida Institución, la Universidad Católica de Colombia, y, en particular, para la Facultad de Psicología: que ambas debían ser conocidas internacionalmente como casas de la sabiduría, pero de la sabiduría que trasciende el simple conocimiento, de la sabiduría que es vida y camino, de la sabiduría que libera y que se revela en las decisiones libres de la persona.

Ciertamente, el comienzo de semejante utopía no fue fácil, pero el poder del trabajo en equipo y el excepcional liderazgo que ejerció el Dr. Vargas al frente de la Facultad hizo posible que se llevaran a cabo grandes logros y realizaciones con las que, sobre todo, hoy se pueda dar testimonio de una afortunada evidencia: la fuerza de la fe en una causa en la que desde un principio sabíamos que valía la pena luchar.

A lo largo de su vida, el Dr. Vargas se destacó por su visión del servicio a la comunidad, por su gran espíritu altruista, y por dedicar todo su esfuerzo para alcanzar las metas que se proponía, entre muchas otras valiosas características de su personalidad. Nació el 17 de junio de 1938 en la localidad de Bolívar (Cauca), en el seno de una familia cristiana y laboriosa. En su juventud, su padre, abogado de profesión, se trasladó con su familia a la ciudad de Popayán, en donde se destacó en el campo del Derecho, llegando a ocupar cargos de gran responsabilidad y figuración; en esos tiempos, el joven Carlos Vargas, siempre con su vocación de servicio a los demás, adelantó estudios de filosofía en el Seminario Conciliar de Popayán, para posteriormente obtener el título de Licenciado en Teología de la Pontificia Universidad Javeriana de Bogotá, seguido de sus estudios de Psicología en la Universidad Católica de Colombia, con lo cual consolidaba su ya importante recorrido académico, que le serviría en su vida profesional para dedicarse en su totalidad al servicio de la educación y la psicología en Colombia.

Tras vincularse al sector de la educación pública como directivo y docente al servicio del Ministerio de Educación, en el año 1980 fue nombrado rector del Colegio Nacional Nicolás Esguerra, en donde tuvo como misión dar inicio y consolidar la jornada de la tarde; allí permaneció durante veinte años y llevó a la institución a obtener los más elevados reconocimientos como institución educativa oficial. Por esta misma época, y haciendo gala de su excepcional capacidad de trabajo, prestó sus servicios a la Universidad Jorge Tadeo Lozano, en Bogotá, en los cargos de Coordinador de Integración Universitaria y Coordinador de Posgrados, y de allí, en el año de 1989, pasó a dirigir el destino de la Facultad de Psicología de la Universidad Católica de Colombia durante más 27 años consecutivos.

En este mismo orden, el Dr. Vargas perteneció a varias agremiaciones profesionales, en las que se destacó por su activa participación e importantes logros. Inicialmente, fue cofundador del Colegio Colombiano de Psicólogos -COLPSIC-, donde ejerció como miembro en su primer Consejo Directivo, para después, desde esa misma condición, participar en la formulación de la propuesta del proyecto de Ley 1090 del 2006, mediante la cual se modificó y reguló el ejercicio profesional de la psicología en Colombia; y entre los años 2007 y 2011, ser elegido Presidente del Capítulo Regional de Bogotá y Cundinamarca de esta misma agremiación. Posteriormente, como miembro en dos periodos de la junta directiva de la Asociación Colombiana de Facultades de Psicología-ASCOFAPSI-, impulsó el

Editor. revistaacta@ucatolica.edu.co Los datos biográficos incluidos fueron elaborados por el Dr. Carlos Vargas Ordóñez y el Dr. Héctor Balmes Ocampo Villegas, Director Programa de Pregrado de la Facultad de Psicología. 
desarrollo científico de este campo del conocimiento para el beneficio general de la sociedad. Esto sin olvidar que también fue cofundador y primer presidente de la Asociación Colombiana de Psicología -ACOLPSIC-.

Finalmente, como decano de la Facultad de Psicología de la Universidad Católica de Colombia, lideró la creación y desarrollo de cuatro Especializaciones -en las áreas de la psicología clínica, educativa, jurídica y de las organizaciones- una Maestría Investigativa en Psicología y un Doctorado en Psicología, al tiempo que posicionaba a la Facultad en la vanguardia de los programas del país, logrando la acreditación de alta calidad para el pregrado en el año 2005 y su renovación durante ocho años en el 2013.

Cabe mencionar, incluso, que en dos oportunidades recibió el reconocimiento público y certificado de la Rectoría de la Universidad por su "probado empeño en la excelencia académica", el cual le permitió a sus estudiantes obtener puntajes superiores en las pruebas de Estado. De igual forma, en el año 2013, por postulación del Departamento de Humanidades de la Universidad y del Consejo Consultivo de la Facultad de Psicología, le fue concedido el reconocimiento institucional "Sapientia aedificavit sibi domum", otorgado cada año al "profesional que desarrolla o ha desarrollado labores académicas sobresalientes en su respectiva disciplina, arte o ciencia, en las humanidades o la política"; y en el 2015, la Rectoría de la Universidad Católica de Colombia le otorgó una mención de reconocimiento por sus 25 años de servicios ininterrumpidos, al mismo tiempo que el Colegio Colombiano de Psicólogos lo postulaba a los premios nacionales "A una vida de entrega a la Psicología" y a "La gestión gremial y a su benéfico impacto social", obteniendo en noviembre de ese mismo año este último reconocimiento.

Desde Acta Colombiana de Psicología expresamos nuestras sentidas condolencias a la familia, amigos y compañeros del Dr. Vargas, y a la vez queremos manifestar que su partida, aunque dolorosa, se constituye en un incentivo para seguir trabajando en beneficio de la Facultad y de la Universidad. Es por esto que invitamos a toda la comunidad a que nos mantengamos con fortaleza para continuar y ser fieles discípulos de sus enseñanzas y de su gran legado. 